\title{
Empirical medical therapy in idiopathic male infertility: Promise or panacea?
}

\author{
Jae Hung Jung ${ }^{1}$, Ju Tae Seo ${ }^{2}$ \\ 'Department of Urology, Yonsei University Wonju College of Medicine, Wonju; '2Department of Urology, Cheil General Hospital, Kwandong University \\ College of Medicine, Seoul, Korea
}

Male factors account for $20 \%-50 \%$ of cases of infertility and in $25 \%$ of cases, the etiology of male infertility is unknown. Effective treatments are well-established for hypogonadotropic hypogonadism, male accessory gland infection, retrograde ejaculation, and positive antisperm antibody. However, the appropriate treatment for idiopathic male infertility is unclear. Empirical medical treatment (EMT) has been used in men with idiopathic infertility and can be divided into two categories based on the mode of action: hormonal treatment and antioxidant supplementation. Hormonal medications consist of gonadotropins, androgens, estrogen receptor blockers, and aromatase inhibitors. Antioxidants such as vitamins, zinc, and carnitines have also been widely used to reduce oxidative stress-induced spermatozoa damage. Although scientifically acceptable evidence of EMT is limited because of the lack of large, randomized, controlled studies, recent systematic reviews with metaanalyses have shown that the administration of gonadotropins, anti-estrogens, and oral antioxidants results in a significant increase in the live birth rate compared with control treatments. Therefore, all physicians who treat infertility should bear in mind that EMT can improve semen parameters and subsequent fertility potential through natural intercourse.

Keywords: Drug therapy; Infertility, male; Pregnancy outcome; Semen analysis

\section{Introduction}

Infertility, defined as the inability of a sexually active couple to conceive after 1 year of regular intercourse without contraception, affects approximately $15 \%$ of couples, and male factors are the cause in $20 \%$ $-50 \%$ of cases [1-3]. Despite technological advances, the cause of male infertility is unknown in $25 \%$ of these cases. Infertility of unknown origin is classified into idiopathic male infertility and unexplained male infertility according to semen quality [3]. Idiopathic male infertility is known as idiopathic oligoasthenoteratozoospermia, which indicates that the men have an unexplained reduction of semen quality. In contrast, unexplained male infertility is defined as infertility of unknown

Received: Jul 25, 2014 · Revised: Sep 1, 2014 · Accepted: Sep 5, 2014 Corresponding author: Ju Tae Seo

Department of Urology, Kwandong University College of Medicine, 17 Seoae-ro 1-gil, Jung-gu, Seoul 100-380, Korea

Tel: +82-2-2000-7585 Fax:+82-2-2000-7787 E-mail:jtandro@cgh.co.kr

This is an Open Access article distributed under the terms of the Creative Commons Attribution Non-Commercial License (http://creativecommons.org/licenses/by-nc/3.0/) which permits unrestricted non-commercial use, distribution, and reproduction in any medium, provided the original work is properly cited. origin with normal sperm parameters [3]. Furthermore, optimal strategies for treating idiopathic male infertility have also remained unclear [4].

The medical treatment of infertility is divided into two main categories: specific and non-specific. Specific treatments are used for certain etiologies such as hypogonadotropic hypogonadism, male accessory gland infection, retrograde ejaculation, and positive antisperm antibody (ASA) [4-6]. Briefly, gonadotropin replacement is considered as an effective therapy in patients with hypogonadotropic hypogonadism that inhibits spermatogenesis and testosterone production. In male accessory gland infection, the presence of leukocytes and microorganisms are responsible for male infertility and antibiotics can be administrated for 2 to 3 weeks. Alpha adrenergic agonists that increase the sympathetic tone of the internal sphincter and vas deferens have been used as an initial medical treatment in patients with ejaculation disorders. ASA can block sperm-egg interaction by immobilizing spermatozoa. Although the clinical significance of ASA is controversial, assisted reproduction techniques are considered to be the treatment of choice [4-6]. In contrast, empirical medical treat- 
ment (EMT), also known as non-specific treatment, has been used in men with idiopathic infertility. EMT can also be divided into two categories based on the mode of action: hormonal treatment and antioxidant supplementation [4-6]. However, scientifically acceptable evidence of EMT efficacy is limited because of the lack of large, randomized, controlled studies. Therefore, we conducted a literature review of studies dealing with commonly used EMTs and the evidence supporting the use of EMT for idiopathic male infertility.

\section{Empirical treatment}

\section{Hormonal treatment}

Hormonal treatment is widely used. It is minimally invasive and has few or no side effects. The hormonal agents employed include gonadotropins, androgens, estrogen receptor blockers, and aromatase inhibitors. These agents influence the hypothalamic-pituitary-gonadal axis to correct what has been termed subclinical endocrinopathy.

\section{1) Gonadotropins}

\section{(1) Background}

The naturally circulating gonadotropins $\mathrm{FSH}$ and LH play a key role in the process of spermatogenesis and steroidogenesis [7]. Furthermore, it is clear that gonadotropins are effective in the treatment of patients with hypogonadotropic hypogonadism. Purified urinary extractions of hCG, FSH, and hMG, along with recombinant forms of FSH and $\mathrm{LH}$, are available for the treatment of idiopathic infertility [5-7].

\section{(2) Results}

Several clinical studies have shown that gonadotropin treatment significantly increases sperm parameters and improves some ultrastructural features of sperm [8-12]. A recent systematic review, including six randomized controlled trials with 456 participants, showed a beneficial effect of gonadotropin treatment in men with idiopathic infertility on live birth and pregnancy rate [13]. Five trials reported spontaneous pregnancies after gonadotropin treatment but only one trial reported live birth rates [10,13-17]. The reviewers concluded that gonadotropin treatment resulted in a statistically significant increase in live births and pregnancies [8]. However, there was no significant improvement in pregnancy rate after IUI and ICSI cycles within the gonadotropin treatment period $[17,18]$. In conclusion, further research is warranted, possibly in combination with artificial reproductive technologies, because of the small number of trials and participants.

\section{2) Androgens}

(1) Background

Androgens are fundamentally important for spermatogenesis. Moreover, male accessory glands that affect seminal constitution and sperm motility, such as the epididymis and seminal vesicles, are also androgen-dependent [3]. Two main theories have been postulated to explain the effect of androgen treatment on male infertility: the direct stimulatory theory and the rebound theory. The stimulatory theory suggests that androgens have a direct stimulatory effect on spermatogenesis and facilitate sperm transport and maturation without influencing pituitary gonadotropin secretion. The rebound theory suggests that androgen therapy suppresses gonadotropin secretion and spermatogenesis, and that the sudden withdrawal of androgens leads to a transient rise in gonadotropins and spermatogenesis [19].

\section{(2) Results}

Only one randomized double blind study of androgen treatment has reported a marginally significant improvement in sperm morphology and a positive effect on pregnancy rate [20]. However, several meta-analyses have indicated that androgens do not improve pregnancy rates or sperm parameters in men with idiopathic infertility $[19,21,22]$. In addition, it is necessary to remember that exogenous testosterone suppresses the hypothalamic-pituitary axis, and thereby leads to a decrease in intratesticular testosterone and spermatogenesis $[23,24]$. Nonetheless, a recent American Urological Association (AUA) survey demonstrated that $25 \%$ of the responding urologists still use exogenous testosterone to treat idiopathic infertility. Surprisingly, a statistically significant difference in practice patterns was seen between general urologists and fellowship-trained urologists; general urologists are more likely to use testosterone than fellowship-trained urologists $(p=0.001)[4]$.

\section{3) Anti-estrogens and aromatase inhibitors}

(1) Background

Estrogen, peripherally aromatized from testosterone by a cytochrome P450 enzyme, provides negative feedback to the hypothalamus and pituitary gland [3]. Anti-estrogens such as clomiphene and tamoxifen block endogenous estrogen by binding to estrogen receptors in the hypothalamus and pituitary. Aromatase inhibitors such as anastrozole, letrozole, and testolactone interfere with the normal synthesis of estrogen by blocking the aromatization of testosterone. Subsequently, these agents block negative feedback effects from estrogen with a resulting increase in gonadotropin secretion, which in turn stimulates spermatogenesis and steroidogenesis $[25,26]$.

\section{(2) Results}

A Cochrane Database review showed that clomiphene and tamoxifen each have a beneficial effect on hormonal levels, such as increased serum testosterone levels, but not enough evidence exists for a positive effect on pregnancy outcomes [27]. However, there is the possibility of a type II error since the lower limit of the confidence interval 
(Cl) in the Cochrane review was 0.99 (odds ratio [OR], 1.56; $95 \% \mathrm{Cl}$, 0.99-2.19). Moreover, a recent meta-analysis with 11 randomized controlled trials found that anti-estrogen therapy was associated with a statistically significant increase in the pregnancy rate (OR, 2.42; $95 \%$ $\mathrm{Cl}, 1.47-3.94 ; p=0.004)$, sperm concentration (weighted mean difference [WMD] 5.24; 95\% Cl, 2.12-88.37; $p=0.001$ ), and sperm motility (WMD, 4.55; 95\% Cl, 0.73-8.37; $p=0.03$ ) [28]. In addition, the authors concluded that clomiphene (50 mg daily) or tamoxifen (20-30 mg daily) administered for 3-6 months had a statistically significant beneficial effect on the pregnancy rate [28].

Studies of the effect of aromatase inhibitors on pregnancy outcomes are limited in number and in the size of the study population. The only double-blinded crossover randomized trial using high-dose testolactone reported no improvement in semen quality and pregnancy rate during the 16 months of the study, despite the demonstration of a lower sex hormone-binding globulin (SHBG) binding capacity with an elevation of free testosterone [29]. Several small studies using letrozole or anastrazole showed a significant increase in sperm parameters as well as a correction of hormonal abnormalities [30,31]. In addition, aromatase inhibitors have been used to treat infertile men with high estrogen or low testosterone-to-estrogen $(\mathrm{T} / \mathrm{E})$ ratios $(<10)$; however, the normal $\mathrm{T} / \mathrm{E}$ ratio is poorly defined and a Korean study has suggested that the proper T/E ratio for treatment is <20 [32].

An AUA survey showed that clomiphene citrate and anastrozole are the most commonly used medications used in EMT for idiopathic infertility [4]. Nevertheless, their benefits are questionable, and further placebo-controlled randomized trials are necessary.

\section{Antioxidant supplementation}

Recently, there has been increasing interest in oxidative stress as an important cause of idiopathic male infertility. Oxidative stress occurs when reactive oxygen species (ROS), which are an inherent byproduct of aerobic life, overcome our natural ability to detoxify ROS-induced damage [33]. In fertile men, ROS production and total antioxidant capacity remain in balance. However, pathological conditions such as infections, autoimmune disorders, chronic disease, advanced age, alcohol consumption, smoking, stress, and obesity result in oxidative stress [34]. Antioxidant defense mechanisms against ROS may be enzymatic or non-enzymatic in nature. Scavenging enzymes within the cellular cytoplasm and antioxidants in the seminal fluid play a key role in antioxidant defense mechanisms [34]. However, relatively low concentrations of scavenging enzymes within the cytoplasm and large amounts of polyunsaturated fatty acids in membranes make spermatozoa susceptible to ROS from lipid peroxidation [35]. As a result, antioxidants in seminal fluid are the most important form of antioxidant defense available to spermatozoa. Antioxidants that are naturally found in semen include vitamins, superoxide dismutase, glutathione, and thioredoxin [35]. Previous studies have reported that high levels of ROS in seminal fluid increased the risk of male infertility [36,37]. In this section, we will review the potential role of various antioxidants as EMT for male infertility. However, there is a possibility of publication bias and the findings are controversial. In addition, the choice and dosage of antioxidants employed are not consistent in the various studies [38].

\section{1) Vitamins}

\section{(1) Background}

Vitamin E can reduce lipid peroxyl radicals through the formation of lipid hydroperoxide and the radical form of vitamin E during the lipid peroxidation process. These vitamin $\mathrm{E}$ radicals are subsequently reduced back to vitamin $\mathrm{E}$ by vitamin C [33]. Therefore, vitamins $\mathrm{E}$ and $\mathrm{C}$ act as a biological scavenging pathway to limit the peroxidation of polyunsaturated fatty acids in the spermatozoa membrane.

\section{(2) Results}

Two randomized trials have found that vitamin E significantly increases sperm motility and function $[39,40]$. Furthermore, a recent Cochrane Database review showed that vitamin E supplementation was associated with a statistically significant increase in the number of live births (OR, 6.44; 95\% Cl, 1.72-24.04; $p=0.006)$ compared to placebo [41]. However, the dose of vitamin $E$ was different in each study. Kessopoulou et al. [40] included couples who were undergoing IVF. Vitamin C supplementation improved sperm parameters, but there have been no randomized controlled trials measuring pregnancy rate as an outcome [42,43].

\section{2) Zinc}

\section{(1) Background}

Zinc (Zn) is a metalloprotein cofactor for DNA transcription and protein synthesis. Previous studies have suggested that $\mathrm{Zn}$ can act as an oxidation inhibitor by binding sulphydryl groups in proteins, and by occupying binding sites for iron and copper in lipids, proteins, and DNA $[44,45]$. Zn concentrations are very high in the male genital organs, particularly in the prostate gland [46]. Recent studies have found that $Z n$ concentrations in seminal fluid were lower in infertile males [47]. In addition, $\mathrm{Zn}$ is necessary for the maintenance of spermatogenesis and optimal function of the testis, prostate, and epididymis [46].

\section{(2) Results}

Wong et al. [48] found that there was no significant improvement in sperm parameters, with the exception of morphology, as determined according to strict criteria in subfertile men. However, Omu et al. $[49,50]$ reported a statistically significant increase in the number of 
births and pregnancies as well as an improvement in sperm parameters.

\section{3) Carnitines}

\section{(1) Background}

Carnitines (L-acetyl carnitine and L-carnitine) are essential compounds in cellular energy metabolism and stabilize spermatozoa membranes through mitochondrial $\beta$-oxidation of long chain fatty acids [51]. L-carnitine regulates the transport of an acetyl group through the cellular membrane by producing L-acetyl carnitine as a bioactive form. These carnitines affect sperm motility, maturation, and spermatogenesis. In addition, carnitines may be responsible for the reduction of excess toxic intracellular acetyl-CoA to protect spermatozoa from oxidative stress [51,52].

\section{(2) Results}

Multiple studies have found that carnitines have beneficial effects on sperm motility and concentration [53-55]. In addition, meta-analysis has shown significant improvement in pregnancy rate when treating men with idiopathic infertility [41,52]. However, there are some differences in the outcomes depending on the form of carnitine used (L-carnitine, L-acetyl carnitine, and L-carnitine plus L-acetyl carnitine) [41,53-55]. Furthermore, Lenzi et al. [54] showed that carnitine levels in seminal fluid did not change despite treatment.

\section{4) Others}

Coenzyme Q10 is a cofactor of the electron transport chain in mitochondria [56]. In 2013, a meta-analysis of three randomized, controlled trials found that coenzyme Q10 has a beneficial effect on sperm parameters, but no effect on either live birth or pregnancy rates [57]. In addition, selenium, folic acid, and N-acetyl cysteine have been also used as EMT and have significantly improved sperm parameters in idiopathic male infertility $[48,58]$. Additionally, pentoxifylline and magnesium, used in the treatment of idiopathic male infertility, have not been shown to be effective in improving sperm parameters or increasing pregnancy rates $[59,60]$.

\section{Combination therapy}

Combination therapies have been studied to improve pregnancy rates. Combinations of different hormonal therapies (anti-estrogen, tamoxifen with an androgen, testosterone undecanoate) in 212 men with idiopathic oligozoospermia and 82 normozoospermic men with female factor subfertility significantly improved sperm parameters and the spontaneous pregnancy rate $[61,62]$. In the past, the European Association of Urology (EAU) guidelines stated that tamoxifen plus testosterone undecanoate appears to be an effective therapy for idiopathic male infertility [63]. However, this recommendation was absent in the most recently published EAU guidelines [64]. Other small randomized trials using combinations of hormonal therapy and antioxidants (anti-estrogen, clomiphene with an antioxidant, Lcarnitine or vitamin E) have shown a beneficial effect on sperm parameters and pregnancy rates $[65,66]$. In addition, other studies with various combinations of antioxidants have been performed. Paradiso Galatioto et al. suggested that commercial preparations of $\mathrm{N}$-acetylcysteine and multi-vitamins are helpful in improving sperm parameters but not in improving the spontaneous pregnancy rate [67]. However, a recent meta-analysis has shown that antioxidants in combination had a positive impact on pregnancy rates [41]. Although there is some disagreement among these studies on the improvement of sperm parameters, treatment with various combinations of $\mathrm{Zn}$, vitamins, selenium, and $\mathrm{N}$-acetylcysteine improved sperm motility and/or concentration [50,58,68-70].

\section{Adverse effects}

With any prescribed therapy, the actual and potential adverse effects associated with each agent need to be considered. Gonadotropin injections may lead to local irritation at the injection site, gastrointestinal symptoms, and breast tenderness [71]. Anti-estrogen and aromatase inhibitor therapy may result in headaches, dizziness, flushing, visual disturbances, impotence, and decreased libido [13,28,31, 71]. Antioxidants commonly cause gastrointestinal symptoms such as nausea, vomiting, and abdominal discomfort [41]. Interestingly, Cavallini et al. [72] reported mild euphoria in all treatment and placebo groups. However, many of the adverse effects related to gonadotropins, anti-estrogens, aromatase inhibitors, and antioxidants are benign and resolve spontaneously. Furthermore, meta-analyses did not find any statistically significant differences between treatment and control groups $[28,41]$.

Currently, testosterone replacement is commonly used in elderly males with late-onset hypogonadism. Testosterone is usually safe, but may cause or aggravate prostatic disease, male breast cancer, sleep apnea, and erythrocytosis [73]. In particular, androgens may have a harmful effect on male fertility via the suppression of the hypothalamic-pituitary axis resulting in decreased production of endogenous testosterone and impaired sperm parameters [23,24]. Although it is widely known that sperm parameters return to normal after cessation of exogenous androgens, we suggest that the various types of testosterones are an inappropriate option for EMT [74,75].

\section{Conclusion}

Many types of EMT have been used in the management of male idiopathic infertility. According to EAU guidelines, FSH may be beneficial in selected patients [64]. A Cochrane Database review showed 
that treatment with oral antioxidants caused a significant increase in the live birth rate compared with control treatments [41]. Therefore, all physicians and urologists who treat infertility should remember that EMT can improve semen parameters and subsequent fertility potential through natural intercourse. Additionally, an effort should be made to establish consistent protocols and recommendations for the use of various forms of EMT.

\section{Conflict of interest}

No potential conflict of interest relevant to this article was reported.

\section{References}

1. Gnoth C, Godehardt E, Frank-Herrmann P, Friol K, Tigges J, Freundl G. Definition and prevalence of subfertility and infertility. Hum Reprod 2005;20:1144-7.

2. Irvine DS. Epidemiology and aetiology of male infertility. Hum Reprod 1998;13 Suppl 1:33-44.

3. Sabanegh EJ, Agarwal A. Male infertility. In: Campbell MF, Walsh PC, Wein AJ, editor. Campbell-Walsh urology. 10th ed. Philadelphia: Saunders Elsevier; 2012. p. 616-47.

4. Ko EY, Siddiqi K, Brannigan RE, Sabanegh ES Jr. Empirical medical therapy for idiopathic male infertility: a survey of the American Urological Association. J Urol 2012;187:973-8.

5. Kumar R, Gautam G, Gupta NP. Drug therapy for idiopathic male infertility: rationale versus evidence. J Urol 2006;176:1307-12.

6. Rittenberg V, El-Toukhy T. Medical treatment of male infertility. Hum Fertil (Camb) 2010;13:208-16.

7. Valenti D, La Vignera S, Condorelli RA, Rago R, Barone N, Vicari E, et al. Follicle-stimulating hormone treatment in normogonadotropic infertile men. Nat Rev Urol 2013;10:55-62.

8. lacono F, Barra S, Montano L, Lotti T. Value of high-dose pure FSH in the treatment of idiopathic male infertility. J Urol (Paris) 1996; 102:81-4.

9. Foresta C, Bettella A, Ferlin A, Garolla A, Rossato M. Evidence for a stimulatory role of follicle-stimulating hormone on the spermatogonial population in adult males. Fertil Steril 1998;69:636-42.

10. Paradisi R, Busacchi P, Seracchioli R, Porcu E, Venturoli S. Effects of high doses of recombinant human follicle-stimulating hormone in the treatment of male factor infertility: results of a pilot study. Fertil Steril 2006;86:728-31.

11. Arnaldi G, Balercia G, Barbatelli G, Mantero F. Effects of long-term treatment with human pure follicle-stimulating hormone on semen parameters and sperm-cell ultrastructure in idiopathic oligoteratoasthenozoospermia. Andrologia 2000;32:155-61.

12. Piomboni P, Serafini F, Gambera L, Musacchio C, Collodel G, Mor- gante $G$, et al. Sperm aneuploidies after human recombinant follicle stimulating hormone therapy in infertile males. Reprod Biomed Online 2009;18:622-9.

13. Attia AM, Abou-Setta AM, Al-Inany HG. Gonadotrophins for idiopathic male factor subfertility. Cochrane Database Syst Rev 2013; 8:CD005071.

14. Knuth UA, Honigl W, Bals-Pratsch M, Schleicher G, Nieschlag E. Treatment of severe oligospermia with human chorionic gonadotropin/human menopausal gonadotropin: a placebo-controlled, double blind trial. J Clin Endocrinol Metab 1987;65:1081-7.

15. Kamischke A, Behre HM, Bergmann M, Simoni M, Schafer T, Nieschlag E. Recombinant human follicle stimulating hormone for treatment of male idiopathic infertility: a randomized, double-blind, placebo-controlled, clinical trial. Hum Reprod 1998;13:596-603.

16. Foresta C, Bettella A, Garolla A, Ambrosini G, Ferlin A. Treatment of male idiopathic infertility with recombinant human folliclestimulating hormone: a prospective, controlled, randomized clinical study. Fertil Steril 2005;84:654-61.

17. Matorras R, Perez C, Corcostegui B, Pijoan Jl, Ramon O, Delgado P, et al. Treatment of the male with follicle-stimulating hormone in intrauterine insemination with husband's spermatozoa: a randomized study. Hum Reprod 1997;12:24-8.

18. Baccetti B, Piomboni P, Bruni E, Capitani S, Gambera L, Moretti E, et al. Effect of follicle-stimulating hormone on sperm quality and pregnancy rate. Asian J Androl 2004;6:133-7.

19. Vandekerckhove $P$, Lilford $R$, Vail $A$, Hughes E. Androgens versus placebo or no treatment for idiopathic oligo/asthenospermia. Cochrane Database Syst Rev 1996;18:CD000150.

20. Gregoriou O, Papadias C, Gargaropoulos A, Konidaris S, Kontogeorgi Z, Kalampokas E. Treatment of idiopathic infertility with testosterone undecanoate. A double blind study. Clin Exp Obstet Gynecol 1993;20:9-12.

21. Liu PY, Handelsman DJ. The present and future state of hormonal treatment for male infertility. Hum Reprod Update 2003;9:9-23.

22. Kamischke A, Nieschlag E. Analysis of medical treatment of male infertility. Hum Reprod 1999;14 Suppl 1:1-23.

23. Fronczak CM, Kim ED, Barqawi AB. The insults of illicit drug use on male fertility. J Androl 2012;33:515-28.

24. de Souza GL, Hallak J. Anabolic steroids and male infertility: a comprehensive review. BJU Int 2011;108:1860-5.

25. Patankar SS, Kaore SB, Sawane MV, Mishra NV, Deshkar AM. Effect of clomiphene citrate on sperm density in male partners of infertile couples. Indian J Physiol Pharmacol 2007;51:195-8.

26. Hayes FJ, Seminara SB, Decruz S, Boepple PA, Crowley WF Jr. Aromatase inhibition in the human male reveals a hypothalamic site of estrogen feedback. J Clin Endocrinol Metab 2000;85:3027-35.

27. Vandekerckhove P, Lilford R, Vail A, Hughes E. Clomiphene or 
tamoxifen for idiopathic oligo/asthenospermia. Cochrane Database Syst Rev 1996;4:CD000151.

28. Chua ME, Escusa KG, Luna S, Tapia LC, Dofitas B, Morales M. Revisiting oestrogen antagonists (clomiphene or tamoxifen) as medical empiric therapy for idiopathic male infertility: a meta-analysis. Andrology 2013;1:749-57.

29. Clark RV, Sherins RJ. Treatment of men with idiopathic oligozoospermic infertility using the aromatase inhibitor, testolactone. Results of a double-blinded, randomized, placebo-controlled trial with crossover. J Androl 1989;10:240-7.

30. Pavlovich CP, King P, Goldstein M, Schlegel PN. Evidence of a treatable endocrinopathy in infertile men. J Urol 2001;165:837-41.

31. Raman JD, Schlegel PN. Aromatase inhibitors for male infertility. J Urol 2002;167:624-9.

32. Lee JS, Park YS, Lee JS, Seo JT. Appropriate Testosterone-to-Estradiol Ratios for Aromatase Inhibitor Usage in Oligoasthenospermic Men. Korean J Androl 2004;22:31-5.

33. Valko M, Leibfritz D, Moncol J, Cronin MT, Mazur M, Telser J. Free radicals and antioxidants in normal physiological functions and human disease. Int J Biochem Cell Biol 2007;39:44-84.

34. Agarwal A, Virk G, Ong C, du Plessis SS. Effect of oxidative stress on male reproduction. World J Mens Health 2014;32:1-17.

35. Sanocka D, Kurpisz M. Reactive oxygen species and sperm cells. Reprod Biol Endocrinol 2004;2:12.

36. Sharma RK, Agarwal A. Role of reactive oxygen species in male infertility. Urology 1996;48:835-50.

37. Chen H, Zhao HX, Huang XF, Chen GW, Yang ZX, Sun WJ, et al. Does high load of oxidants in human semen contribute to male factor infertility? Antioxid Redox Signal 2012;16:754-9.

38. Jensen TK, Skakkebaek NE, Jorgensen N, Jensen MB, Juul A. Antioxidants and male subfertility--a survey of a Cochrane review. Ugeskr Laeger 2011;173:3253-5.

39. Suleiman SA, Ali ME, Zaki ZM, el-Malik EM, Nasr MA. Lipid peroxidation and human sperm motility: protective role of vitamin $E$. J Androl 1996;17:530-7.

40. Kessopoulou E, Powers HJ, Sharma KK, Pearson MJ, Russell JM, Cooke ID, et al. A double-blind randomized placebo cross-over controlled trial using the antioxidant vitamin E to treat reactive oxygen species associated male infertility. Fertil Steril 1995;64:825-31.

41. Showell MG, Brown J, Yazdani A, Stankiewicz MT, Hart RJ. Antioxidants for male subfertility. Cochrane Database Syst Rev 2011: CD007411.

42. Dawson EB, Harris WA, Rankin WE, Charpentier LA, McGanity WJ. Effect of ascorbic acid on male fertility. Ann N Y Acad Sci 1987; 498:312-23.

43. Akmal M, Qadri JQ, Al-Waili NS, Thangal S, Haq A, Saloom KY. Improvement in human semen quality after oral supplementation of vitamin C. J Med Food 2006;9:440-2.

44. Bray TM, Bettger WJ. The physiological role of zinc as an antioxidant. Free Radic Biol Med 1990;8:281-91.

45. Zago MP, Oteiza PI. The antioxidant properties of zinc: interactions with iron and antioxidants. Free Radic Biol Med 2001;31: 266-74.

46. Gavella M, Lipovac V, Vucic M, Sverko V. In vitro inhibition of superoxide anion production and superoxide dismutase activity by zinc in human spermatozoa. Int J Androl 1999;22:266-74.

47. Turk S, Mandar R, Mahlapuu R, Viitak A, Punab M, Kullisaar T. Male infertility: decreased levels of selenium, zinc and antioxidants. J Trace Elem Med Biol 2014;28:179-85.

48. Wong WY, Merkus HM, Thomas CM, Menkveld R, Zielhuis GA, Steegers-Theunissen RP. Effects of folic acid and zinc sulfate on male factor subfertility: a double-blind, randomized, placebocontrolled trial. Fertil Steril 2002;77:491-8.

49. Omu AE, Dashti H, Al-Othman S. Treatment of asthenozoospermia with zinc sulphate: andrological, immunological and obstetric outcome. Eur J Obstet Gynecol Reprod Biol 1998;79:179-84.

50. Omu AE, Al-Azemi MK, Kehinde EO, Anim JT, Oriowo MA, Mathew TC. Indications of the mechanisms involved in improved sperm parameters by zinc therapy. Med Princ Pract 2008;17:108-16.

51. Jeulin C, Lewin LM. Role of free L-carnitine and acetyl-L-carnitine in post-gonadal maturation of mammalian spermatozoa. Hum Reprod Update 1996;2:87-102.

52. Zhou X, Liu F, Zhai S. Effect of L-carnitine and/or L-acetyl-carnitine in nutrition treatment for male infertility: a systematic review. Asia Pac J Clin Nutr 2007;16 Suppl 1:383-90.

53. Balercia G, Regoli F, Armeni T, Koverech A, Mantero F, Boscaro M. Placebo-controlled double-blind randomized trial on the use of L-carnitine, L-acetylcarnitine, or combined L-carnitine and L-acetylcarnitine in men with idiopathic asthenozoospermia. Fertil Steril 2005;84:662-71.

54. Lenzi A, Sgro P, Salacone P, Paoli D, Gilio B, Lombardo F, et al. A placebo-controlled double-blind randomized trial of the use of combined I-carnitine and I-acetyl-carnitine treatment in men with asthenozoospermia. Fertil Steril 2004;81:1578-84.

55. Peivandi S, Abasali K, Narges M. Effects of L-carnitine on infertile men's spermogram; a randomised clinical trial. J Reprod Infertil 2010;10:331.

56. Mancini A, Conte B, De Marinis L, Hallgass ME, Pozza D, Oradei A, et al. Coenzyme Q10 levels in human seminal fluid: diagnostic and clinical implications. Mol Aspects Med 1994;15 Suppl:s249-55.

57. Lafuente R, Gonzalez-Comadran M, Sola I, Lopez G, Brassesco M, Carreras R, et al. Coenzyme Q10 and male infertility: a meta-analysis. J Assist Reprod Genet 2013;30:1147-56.

58. Safarinejad MR, Safarinejad S. Efficacy of selenium and/or N-ace- 
tyl-cysteine for improving semen parameters in infertile men: a double-blind, placebo controlled, randomized study. J Urol 2009; 181:741-51.

59. Wang C, Chan CW, Wong KK, Yeung KK. Comparison of the effectiveness of placebo, clomiphene citrate, mesterolone, pentoxifylline, and testosterone rebound therapy for the treatment of idiopathic oligospermia. Fertil Steril 1983;40:358-65.

60. Zavaczki Z, Szollosi J, Kiss SA, Koloszar S, Fejes I, Kovacs L, et al. Magnesium-orotate supplementation for idiopathic infertile male patients: a randomized, placebo-controlled clinical pilot study. Magnes Res 2003;16:131-6.

61. Adamopoulos DA, Pappa A, Billa E, Nicopoulou S, Koukkou E, Michopoulos J. Effectiveness of combined tamoxifen citrate and testosterone undecanoate treatment in men with idiopathic oligozoospermia. Fertil Steril 2003;80:914-20.

62. Adamopoulos DA, Nicopoulou S, Kapolla N, Karamertzanis M, Andreou $E$. The combination of testosterone undecanoate with tamoxifen citrate enhances the effects of each agent given independently on seminal parameters in men with idiopathic oligozoospermia. Fertil Steril 1997;67:756-62.

63. Dohle GR, Colpi GM, Hargreave TB, Papp GK, Jungwirth A, Weidner W, et al. EAU guidelines on male infertility. Eur Urol 2005;48: 703-11.

64. Jungwirth A, Giwercman A, Tournaye H, Diemer T, Kopa Z, Dohle $\mathrm{G}$, et al. European Association of Urology guidelines on Male Infertility: the 2012 update. Eur Urol 2012;62:324-32.

65. Moradi M, Moradi A, Alemi M, Ahmadnia H, Abdi H, Ahmadi A, et al. Safety and efficacy of clomiphene citrate and L-carnitine in idiopathic male infertility: a comparative study. Urol J 2010;7:188-93.

66. Ghanem H, Shaeer O, El-Segini A. Combination clomiphene citrate and antioxidant therapy for idiopathic male infertility: a randomized controlled trial. Fertil Steril 2010;93:2232-5.

67. Paradiso Galatioto G, Gravina GL, Angelozzi G, Sacchetti A, Innominato PF, Pace $G$, et al. May antioxidant therapy improve sperm parameters of men with persistent oligospermia after retrograde embolization for varicocele? World J Urol 2008;26:97-102.

68. Greco E, lacobelli M, Rienzi L, Ubaldi F, Ferrero S, Tesarik J. Reduction of the incidence of sperm DNA fragmentation by oral antioxidant treatment. J Androl 2005;26:349-53.

69. Scott R, MacPherson A, Yates RW, Hussain B, Dixon J. The effect of oral selenium supplementation on human sperm motility. $\mathrm{Br}$ J Urol 1998;82:76-80.

70. Rolf C, Cooper TG, Yeung CH, Nieschlag E. Antioxidant treatment of patients with asthenozoospermia or moderate oligoasthenozoospermia with high-dose vitamin C and vitamin E: a randomized, placebo-controlled, double-blind study. Hum Reprod 1999; 14:1028-33.

71. Derman SG, Adashi EY. Adverse effects of fertility drugs. Drug Saf 1994;11:408-21.

72. Cavallini G, Ferraretti AP, Gianaroli L, Biagiotti G, Vitali G. Cinnoxicam and L-carnitine/acetyl-L-carnitine treatment for idiopathic and varicocele-associated oligoasthenospermia. J Androl 2004; 25:761-70.

73. Kim JW, Moon DG. Diagnosis and treatment of sexual dysfunctions in late-onset hypogonadism. Korean J Urol 2011;52:725-35.

74. Jan Z, Pfeifer M, Zorn B. Reversible testosterone-induced azoospermia in a 45-year-old man attending an infertility outpatient clinic. Andrologia 2012;44 Suppl 1:823-5.

75. Nudell DM, Monoski MM, Lipshultz LI. Common medications and drugs: how they affect male fertility. Urol Clin North Am 2002; 29:965-73. 